\title{
A Literature Review of the Influence of Social Exclusion on Consumer Behavior and Prospects
}

\author{
Xiaodan Yang \\ School of Management, Jinan University School, Guangzhou, China \\ Email: mxn0909@163.com
}

How to cite this paper: Yang, X.D. (2019) A Literature Review of the Influence of Social Exclusion on Consumer Behavior and Prospects. American Journal of Industrial and Business Management, 9, 764-779. https://doi.org/10.4236/ajibm.2019.93050

Received: March 5, 2019

Accepted: March 24, 2019

Published: March 27, 2019

Copyright (c) 2019 by author(s) and Scientific Research Publishing Inc. This work is licensed under the Creative Commons Attribution International License (CC BY 4.0).

http://creativecommons.org/licenses/by/4.0/

\section{(c) (i) Open Access}

\begin{abstract}
Social exclusion is a common and threatening social experience that affects individual psychology and behavior. In particular, when there are social exclusion cues in the marketing environment, it will have an important impact on consumers' behavioral decisions. However, in existing studies, the relationship between social exclusion and consumption behavior is still in chaos. Some scholars believe that individuals who experience social exclusion are more inclined to make nostalgic consumption or purchase corresponding products that symbolize group identity. However, other scholars pointed out that individuals who experience social exclusion are more inclined to conspicuous and unique consumption. It can be seen that when consumers are excluded by the society, their behavioral responses will deviate, and consumers will eventually use what kind of consumption behavior to make up for their internal defects. This problem has not been effectively solved. Therefore, this paper takes the social exclusion in consumption as the research object, first elaborates the concept of social exclusion, and then reviews the impact of social exclusion on people's psychological needs. On this basis, the research status of social exclusion in the field of consumer behavior is summarized, and the consumer behavior generated by the social exclusion is summarized into two kinds of consumer behavior, namely relationship compensation behavior and ability compensation behavior. Finally, the future research direction of the influence of social exclusion on consumption behavior is prospected.
\end{abstract}

\section{Keywords}

Social Exclusion, Psychological Needs, Consumer Behavior

\section{Introduction}

We all experience the breakdown of such a relationship, being ignored by 
teammates in roundtable discussions, or receiving rejection letters from a favorite company or university, etc. These experiences make us feel rejected, ignored, or rejected. Social rejection is a common and threatening experience. According to a report from the European urban knowledge network, 124 million people (about a quarter of Europeans) in Europe have experienced various forms of social exclusion, and eastern, more collectivist countries are likely to experience more. More researchers predict that we will experience about 25,000 rejections in our lifetime [1]. However, the desire for social relations is one of the basic human needs. The existence of social exclusion hinders this deep-rooted motivation and has a significant impact on people's psychological and physiological functions. For example, social exclusion will damage the cognitive function of individuals [2], make them fall into a state of numbness, negativity and meaninglessness [3], impair self-regulation [4] and hinder their logical reasoning ability [5].

Given the wide range of social exclusion and the severity of the consequences, social exclusion has led to continued attention and discussion in multiple research areas. In the past two decades, scholars in various fields such as social psychology [6], political economy [7], and marketing [8] have conducted in-depth research on social exclusion. In particular, consumer behavior, which is closely related to psychology, has a strong practical and theoretical value for the study of social exclusion. In the marketing environment, there are many forms of social exclusion. For example, the superiority conveyed by luxury advertisements, the neglect of service personnel, and refusal can all lead to the rejection of consumers [9] [10]. Social exclusion in the marketing context directly or indirectly affects the consumer psychology and behavior of the excluded. In recent years, scholars have done a rich research on the consequences of social exclusion consumer behavior. For example, scholars have found that consumers who are excluded are more likely to spend money on products that symbolize member groups than those who are not excluded, and are more willing to match the consumption activities of group members [8], but they will also pay more attention to themselves [11] and are eager for the attention of others [8] [12], while emphasizing the uniqueness of the self [13].

Based on the research results in the field of psychology, this paper first expounds the concept of social exclusion, and then reviews the impact of social exclusion on people's psychological needs. On this basis, the research status of social exclusion in the field of consumer behavior is summarized, and consumers' consumption behaviors against social exclusion, namely, relationship compensation behavior and ability compensation behavior, are summarized. Finally, this paper looks forward to the future research direction of social exclusion on the impact of consumer behavior, hoping to provide inspiration for subsequent consumer research.

\section{Definition of Social Exclusion}

At the current stage, in international psychology research, there are several referential methods for social exclusion, namely social exclusion, rejection, social 
rejection, interpersonal rejection, ostracism, social ostracism, interpersonal ostracism, in which social exclusion, rejection and ostracism are The three most common forms of social exclusion.

Social rejection (e.g., being rejected, isolated or excluded) sometimes accompanied by a clear dislike, while others are not [4] [14] is a common and threatening experience. Social exclusion is almost It can happen in all aspects of social life, such as being in a party or office conversation, ending a romantic relationship, or receiving a rejection letter from a business or college.

Social exclusion, including social rejection, social exclusion, and ostracism, can result in a lower sense of belonging and an unacceptable feeling. Although there are a large number of studies on social exclusion, exile, and rejection, few studies have been able to determine whether these terms are separate phenomena of description or can be replaced. Although some scholars try to distinguish these terms from a psychological and semantic point of view [15] [16], in fact, there is no empirical study to prove the difference between the three [14].

Williams [17] defines exile as being ignored or rejected, in the absence of excessive explanation or more obvious negative concerns. Exile is often studied first in the laboratory environment and rarely verified by field experiments or interview experiments.

Twenge [18] defines social exclusion as being excluded, isolated, and alone, including explicit statements and unclear statements that do not like it. Typical rejection manipulations are generally separated after the subjects have known each other, or the hypothetical outcome of the test being likely to be lonely in the future.

The refusal of Leary [15] is that individuals are told that they no longer belong to an organization or group, or that others do not want to interact with individuals.

From the definition of social exclusion by different researchers, the concept of social exclusion is defined around a center, that is, the need for individuals to belong to a group or to establish relationships with others cannot be met. However, different researchers have not agreed on the reasons for individuals and how they are rejected by groups. As a result, they have different operational definitions of social exclusion in research.

Due to the diversity, complexity and heterogeneity of social exclusion phenomena, scholars distinguish different types of social exclusion constructs and define and compare the phenomena represented by different terms. Scholars have found through empirical research that different types of social exclusion can cause different reactions, and only a term "social exclusion" covers all exclusion phenomena that may lead to inconsistent research results. Thus, social exclusion is differentiated in a certain dimension.

According to the perspective of self-attribution cognition, the distinction is excluded because of self-mediocrity and excluded because of self-excellence [19], that is, because they are inferior to others or over others in certain aspects, such as study, life, work, etc., to rejection. According to the intensity of social exclu- 
sion, it is divided into partial ostracism and complete ostracism [20] [21]. According to the type of relationship defects, it is divided into emotional defects (lack of intimate connections, from spouses, parents) and social defects (lack of social connections, from friends, colleagues) [22]. According to whether social exclusion is clearly and directly conveyed, it is classified as "being rejected" and "being ignored" [11] [23]. "Rejected" means that the individual is directly and explicitly informed that it is not popular in social relations; "neglected" means indirectly and implicitly making it known that it is not popular in social relations.

\section{Social Exclusion and Psychological Needs}

\subsection{Social Exclusion and Single Psychological Needs}

Individual psychological needs are not static, changes in self-awareness, external environmental stimuli, etc. will bring about changes in individual psychological needs. Inspired by certain circumstances, different individuals induce the same or different types of psychological needs. As a social animal, human beings have strong social attributes, while social exclusion represents the deterioration of individual social relations. It is an important environmental stimulus for individuals, and what social exclusion will bring to individuals. What are the psychological needs and psychological needs?

The article sorts out and reviews previous studies and finds that social exclusion threatens four kinds of psychological needs: belongness, self-esteem, control, meaningful existence [24] [25]. Social exclusion first means the deterioration of social relations and an important signal of poor network relations in social interactions. The attribution of belonging refers to people's desire to form and maintain positive interpersonal relationships [26]. Therefore, social exclusion will make the excluded people feel that they are excluded from others, and they cannot integrate into the group, and thus cannot acquire the sense of belonging of the group. At the same time, social exclusion will also make the individual feel that others attach less importance to this relationship than themselves. Reduce the relational value. Even in the early stage of research, some scholars regard the negative impact of social exclusion on individual belonging as a part of the definition of social exclusion, and believe that hurting individual belonging is an indispensable key indicator of social exclusion [16] [18]. As a basic interpersonal relationship, attribution needs to promote re-association with others when it is threatened [27]. For example, consumers with a lack of belonging are more inclined to purchase products related to group identity, such as school wristbands, etc., but also hide their real consumption habits instead of imitating the consumption preferences of social objects [8]; individuals lacking a sense of belonging Will be more fond of nostalgic products, by evoking their sense of contact with the same consumer groups in the past, and then to meet the needs of attribution [28].

Social exclusion threatens the need for self-esteem. The sociological hypothe- 
sis suggests that the function of the self-esteem system is to act as a sociologist, to monitor the extent to which a person is accepted/rejected, and to motivate individuals to take certain actions in order to minimize the possibility of exclusion [26]. This also indicates that self-esteem is highly sensitive to changes in the perceived inclusive state. The threat of self-esteem makes individuals think that they are not good enough, not confident enough or even insecure [29]. The study points out that in this case, individuals will be more friendly in interpersonal relationships in order to maintain their image in others' minds [30].

Social exclusion can lead to a decline in the level of individual control perception [31]. Interpersonal relationship is an important component of the social environment. When an individual perceives problems in his or her own social relationship, he or she will experience the feeling of losing control of interpersonal relationships and social environment. Moreover, as a group-based creature, human beings rely on the formation of social systems to avoid the various risks encountered in the process of survival. Social relations have become an important way for individuals to accomplish goals and avoid risks. Social tensions brought about by social exclusion are not only It is perceived that the individual is unable to grasp his or her social environment, and it will also bring the individual's powerlessness to their own ability to survive and develop [32]. Similar conclusions have been confirmed in the meta-analysis [33]. However, similar to the research results of self-esteem demand, there are still researchers who question the conclusions of social exclusion-induced individual control needs [34], which brings the academic supplement and discussion of the corresponding content [35].

In addition, studies have shown that individuals who are socially excluded will experience more severe changes in their psychological needs, and may even feel that their sense of life is reduced [36]. Attribution theory shows that when an individual is stimulated by the outside world, the source of the success or failure factor is measured. The individual may attribute the root cause of the problem to its own factor (internal control) or from the external environment (external control). When the excluded are socially excluded, they may think that their own reasons have resulted in a situation that is not accepted by others, that is, negative self-attribution in exclusion, causing oneself to doubt self-worth and meaning [36]. There are also researchers who have indirectly demonstrated the role of social exclusion in the need for individual sense of meaning in other relevant studies of social exclusion [11].

\subsection{Social Exclusion to the Integration of Psychological Needs}

In the past studies, some scholars have also sorted out and summarized the changes in consumer psychological needs under the influence of socialexclusion. Williams [14] relies on the basic needs theory, integrates the psychological changes of consumers after social exclusion, and proposes that social exclusion has little effect on individual autonomy, but it will stimulate the two basic psy- 
chological needs of individuals, relationship needs and effectiveness (ability) demand.

The demand-threat model proposed by Williams [14] pointed out that social exclusion can arouse the sense of threat of individual relationship needs, which is reflected in the corresponding threat of the belonging and self-esteem of the excluded. At the same time, social exclusion will also lead to individual performance needs. The increase in threats is manifested in the corresponding threat of the sense of control and the existence of the excluded. Relationship needs and performance requirements are a good reflection of human needs at both levels within and between individuals [37]. For the needs of individuals, each individual hopes to establish a good interpersonal relationship, and hopes to get a sense of belonging and respect in the group life, while the attribution needs and respectful needs are very good to depict the individual in the group life, two aspects of demand for social relations. The performance requirement is a good expression of the individual's urgent need for self-ability. Compared with the relationship demand, the performance demand is a more internalized form of demand. It pays more attention to the ability of independent individuals to solve problems themselves, the control of the environment and the search for the meaning of self-life.

Then, by summarizing the behavioral responses of different psychological needs, it can be found that when the relationship needs are threatened, the attribution and self-esteem are reduced, and the individual may pay attention to the establishment of their relationship with others, and they try to symbolize the group of members. Products, matching the consumption of member groups [8], etc. to maintain or strengthen the relationship with the member groups to meet their relationship needs.

When the performance demand is threatened, the sense of control and presence are reduced, the individual will pay more attention to the self's ability, or the sense of self-control or presence, they will be eager to get the attention of others [8] [12], trying to pass Desire for groups to establish connections, emphasizing self-ability or upgrading status [13] to meet their performance needs.

\section{Demand and Consumption Behavior under the Influence of Social Exclusion}

With the penetration of social networks and the integration of social and shopping elements, consumers are always in the social network. Therefore, as the main stimulus in social network-social exclusion-affects the psychological needs of consumers. In this case, it will have an important impact on its behavior [38]. For example, excluded consumers will purchase specific products or brands through specific consumption decisions in response to the psychological needs of social exclusion stimuli. Based on the existing social exclusion theory, domestic and foreign scholars make reasonable inference and empirical research in the field of consumer behavior, enriching and deepening the results of social exclu- 
sion in interpersonal relationship behavior. This paper focuses on the related research on psychological needs and consumer behavior under the influence of social exclusion, and summarizes the behavioral responses of two major categories of consumers to social exclusion, namely, the relationship between compensatory consumer behavior and performance-compensatory consumer behavior.

\subsection{Relationship Compensatory Consumer Behavior}

Social testing theory believes that social exclusion hinders people's relationship and reduces the self-esteem of the excluded. Therefore, based on people's desire to obtain a sense of belonging and to repair social relationships, individuals usually adopt corresponding consumer behaviors to obtain social connections and social support [39]. Consistent with this view, the study found that excluded people are more concerned with using new relationships to construct relationship bonds than those who are accepted [40], more sensitive to social recognition [34], and more likely to cater to others, the point of view [24]. Previous studies have found that excluded people are more likely to carry out consumer behavior, prefer nostalgic, anthropomorphic products and soft touch products [41] [42].

1) Herd behavior

Based on the basic needs of seeking social identity and maintaining intimate relationships, consumers are willing to invest or sacrifice important resources such as time and money to ensure continued happiness [43]. In the absence of social support, consumers may need and seek more money to get what they want from the social system. They will take certain financial risks by increasing the instrumentality of money [32], and carry out strategic public consumption to cope with the threat of social exclusion on their relationship needs, so as to obtain the goodwill and social acceptance of others [8]. The study found that subjects experiencing social rejection were more likely to buy products that symbolized group membership, align their consumption preferences with their social interaction partners, choose foods that their peers liked but not them, and even try drugs in order to gain acceptance from others [8]. In addition, the consumer's response to social exclusion is still largely reflected in its brand selection behavior. For example, consumers who experience social exclusion will adopt the same brand as their reference group to enhance their sense of belonging, because the symbolic meaning of a particular brand itself can help consumers establish relationships with others, reduce exclusion, and enhance social groups, sense of belonging [44]. However, Wan, $\mathrm{Xu}$ and Ding [12] argue that consumers' conspicuous consumption behaviors against social exclusion depend on their interpretation of the causes of exclusion [31]. When the excluded individual believes that the reason for rejection is stable and immutable, the consumer will choose a unique product to distinguish himself from others, and when the individual believes that the cause of rejection is variable, the consumer will choose the public products to make yourself a member of the group. It also explores the 
self-affirmation, resource availability and changeability factors to regulate this hereditary consumption decision.

2) Nostalgic and anthropomorphic products

Studies have shown that when people feel lonely or their needs are not met, people often recall their interactions with intimate people [45], flip through photos, read letters, and even consume previously popular brands or products, to get connections with important people in the past [46]. Based on this, when individuals are socially excluded, consumers will have certain preferences for products that are common in fashion (pregnancy, adolescence, childhood, and even before birth), popular fashion, or widely circulated (nostalgic products) [41]. For example, in social exclusion scenarios, individuals have an increased preference for popular movies, food, and cars in the past [47]. However, other studies have shown that different rejection attributions can affect the preference of rejected individuals for nostalgic products. Specifically, the study found that individuals who were excluded only because of mediocrity had a higher willingness to purchase under the nostalgic brand activation strategy, in which the past time orientation played a mediating role in the relationship; and the consumers who were excluded because of excellence were Under the innovative brand activation strategy, the purchase intention is higher, and the future time orientation plays a mediating role in the relationship between the two [19].

In addition, the lack of social connections makes individuals tend to give inanimate objects, such as technology products, private souvenirs, photos or pets, and other personality traits, and show more attachment [48], to some extent People seek for a sense of belonging. Therefore, individuals who are socially excluded will be more inclined to purchase or choose anthropomorphic products; and the perception of social characteristics of products plays a mediating role between social exclusion and the purchase of anthropomorphic products [42]. Moreover, exposure to or interaction with anthropomorphic consumer products (i.e., products characterized by design, interaction, intelligence, responsiveness, and/or personality) can mitigate the effects of social exclusion, but when alerted to the product [49]. This role in reducing the effects of social exclusion disappears when real interpersonal interactions are not provided [49].

\subsection{Performance Compensatory Consumer Behavior}

According to the theory of psychological needs, the requirement of efficiency refers to the individual's need to show his own control of the external environment through behavior. That is, when individuals engage in various activities, they need to demonstrate their ability to control the surrounding environment through behavior or other forms, and demonstrate their ability to solve problems and overcome difficulties, and the desire to express and demonstrate the need is the effectiveness demand. When an individual's performance needs are threatened, the individual will pay more attention to the self [11] and desire the attention of others [14] while emphasizing the uniqueness of the self [13]. Stu- 
dies have found that when individuals are socially excluded, they will perform compensatory consumption.

Although studies have shown that excluded consumers are more likely to spend money on products that symbolize member groups and actively match the consumption interactions of member groups [8], subsequent studies have found that excluded individuals will reject whether the reasons for the occurrence are stable or the inference of the possibility of regaining social acceptance affects whether they adopt a hereditary consumption behavior and seek unique consumption under specific circumstances [12]. In addition, social exclusion makes individuals willing to spend more money on conspicuous consumption, such as the purchase of luxury goods. This is because luxury goods can meet the individual's consumer identity needs, gain the attention of others, and produce superiority [50]. Moreover, when individuals experience social exclusion from their belonging groups, they significantly increase their willingness to purchase counterfeit goods [51]. On the other hand, in the marketing environment, the attitude of luxury advertising and luxury shop clerk can also cause consumers to be rejected [9]. Intuitively, this rejection should reduce consumers' attitude towards luxury brands, preference. Ward and Dahl's research found that when consumers are excluded from the sales of luxury brands they are craving, their attitude towards the luxury brand and their willingness to buy will increase [10]; and for those who will image themselves Consumers who are eager for the luxury brand image will have a stronger brand attitude and willingness to purchase after the social exclusion. This means that excluded individuals will respond to the threat of social exclusion through different consumer behaviors in specific situations. For example, Williams [14] divides the form of social exclusion into neglect and rejection, and empirical studies have shown that the behavioral responses of excluded people to different forms of social exclusion will be different. Specifically, social exclusion caused by rejection increases consumer willingness to donate, and social exclusion caused by neglect increases consumer conspicuous consumption [11]. This is because direct rejection threatens the need for self-esteem that is excluded, so that being excluded is more inclined to re-establish relationship by helping others and donating behavior to enhance self-esteem; neglect will have a sense of control and existence for the individual. The meaning creates a threat, which leads to the conspicuous consumption behavior of the excluded, in order to manifest themselves and regain the attention of others. In addition, the study found that gender affects the tendency of excluded to show off consumer behavior [52]. Male consumers are more inclined to choose high-income income while female consumers are more inclined to purchase negative-looking products to cope with the negative effects of social exclusion. At the same time, female consumers who experience social exclusion are more inclined to respond to the threat of interpersonal relationships brought about by social exclusion through external consumption, and gain social attention and social acceptance [37]. 


\section{Summary and Research Outlook}

\subsection{The Purpose and Significance of the Study}

According to previous studies, individuals who suffer from social rejection experience a series of negative physiological and psychological responses [53] [54], and even produce aggressive tendencies and anti-social behaviors [36]. It is necessary to the exclusion of individual psychological counseling, guide the correct behavior. An excluded person tend to have multiple social identities, one is that a consumer. Therefore, in the marketing situation, how to rejection of the psychological dredge and guide the correct behavior for rebuilding the sense of belonging, to reduce the anti-social behavior, and promote social stability is very important. On the other hand, there are many forms of social exclusion in the marketing environment. For example, the superiority of luxury brand conveys, exclusive, and distance is a symbol of social isolation and social exclusion, therefore, compared with the luxury advertisement, luxury AD more can cause consumers sense of rejection [9], and in the service marketing there also exist the scene to ignore, rejection, and other forms of social exclusion [10]; therefore, it is necessary for marketers to understand and help the excluded from the perspective of consumer behavior, reduce or prevent the social exclusion phenomenon in the marketing context, and timely make up for the negative impact of social exclusion on consumers.

\subsection{Summary and Combing of Previous Studies}

In the related research on social exclusion, the research field of psychology has achieved rich research results. In recent years, scholars at home and abroad have begun to apply the results of social exclusion in psychology research to the field of marketing, mainly consumer behavior research, focusing on the changes in the psychological needs of consumers in the experience of social exclusion and more a change in the consumption decisions taken. Different scholars have drawn different conclusions about the impact of social exclusion on consumer behavior. For example, in terms of emotional response, social exclusion can cause individuals to have emotional grief or emotional numbness; in terms of behavioral responses, social exclusion can cause individuals to pro-social or anti-social and even evade and retreat. This paper focuses on the social exclusion threats psychological needs, focusing on the impact of social exclusion on consumer behavior in the context of changes in psychological needs, and draws two different consumer behaviors, namely, relationship compensation consumption and performance compensation consumption. When social exclusion threatens the need for belonging or self-esteem, herd consumption and nostalgic or anthropomorphic consumption can help consumers reduce the impact of social exclusion; and when social exclusion threatens the meaning of control or existence, flaunt consumption or unique consumption can help consumers reduce the impact of reduced efficacy from social exclusion. Recent research on social exclusion has mostly combined different consumer behavioral responses, and argued 
that different interpretations of social exclusion experiences or different forms and causes of social exclusion threaten different psychological needs, thus affecting people's consumption choices.

\subsection{Limitations and Future Research Prospects}

In general, the current research on social exclusion in the field of marketing is only the tip of the iceberg, and scholars still need to conduct in-depth discussions and research in this field. Future research can further examine the following aspects:

First of all, through the combing and summarizing of the literature, we can find that the relationship between social exclusion and various consumer behaviors needs to be further clarified. From the perspective of relationship needs, excluded individuals may be more inclined to choose from the crowd, prefer nostalgic, anthropomorphic, and mass products, and are willing to pay higher prices for service products that can provide interpersonal contact and interactive opportunities. From the perspective of performance requirements, the excluded individuals will pay more attention to their own effectiveness, emphasizing the uniqueness of the self, and will prefer the unique products, the products that show the status or the luxury goods and even the counterfeit goods. Therefore, in addition to the consumer behavior reactions that have been involved, there is still a large amount of research space available for expansion.

In addition, the internal mechanism of the impact of social exclusion on consumer behavior remains to be explored. The mediation process of social exclusion in existing research is mainly from the perspective of changes in psychological needs. Other possible mediator variables, such as emotions and cognition, have not been empirically supported. Although studies have used basic demand types as an intermediary mechanism and have been demonstrated through empirical research, future research needs to further test these research findings, while also considering the role of other mediator variables.

Second, according to previous research, external and objective environmental factors can trigger social exclusion, such as luxury advertising and the attitude of sales people in luxury stores can make consumers feel excluded. But beyond that, empirical research on the predisposing factors of social exclusion is extremely limited. Once social exclusion occurs, it becomes an established fact. The existing research only explains the impact of this fact on the parties and explains the impact, but it cannot predict or prevent the occurrence of social exclusion. Therefore, it is necessary to explore the incentives of social exclusion in future research.

Furthermore, research on the sources of social exclusion in the field of psychology has been continually advancing in recent years, and the manipulation of social exclusion in the field of marketing rarely distinguishes its sources of exclusion. Future research can study the impact of social exclusion from different sources of exclusion on consumer behavior in the classification of belonging 
groups. At present, there are few clear and reasonable reasons for the manipulation of social exclusion. The subjects suddenly fail to pass the companion's pass (network throwing paradigm), or the defendant will live a lonely life without friends. Paradigm or the subject was directly rejected, but did not get any reason for rejection, although such manipulation can ensure the pure effect of the experiment, but it ignores the complexity of the experience of social exclusion. In real life, people will not refuse or exclude others for no reason, and people will accept or exclude others based on their specific perception or judgment of others. Moreover, when individuals are victims of exclusion (especially when there is no obvious reason), they will also consider the possible judgments and opinions of the exclusionists. Therefore, the study can also explore the legality of social exclusion on consumer behavior influences.

Finally, theoretical and empirical studies have shown that social exclusion may have positive and negative effects on excluded individuals. Therefore, it is important to study the boundary conditions of social exclusion on consumer behavior. Subsequent research needs to explore the fact that individuals who are excluded in those cases produce positive and healthy consumer behavior; in which cases individuals who are excluded will produce negative, unhealthy consumer behavior. Personal traits-such as refusal sensitivity, self-construction, self-esteem, etc., characteristics of social relationships-such as the closeness of relationships, the possibility of substitution, the expectation of relationship repair, the perceived unfairness of social exclusion, and the characteristics of consumer goods For example, the degree of ownership of the product, brand personality, etc., may become the adjustment variables of the impact of social exclusion on consumer behavior.

\section{Conflicts of Interest}

The author declares no conflicts of interest regarding the publication of this paper.

\section{References}

[1] Zadro, L. and Gonsalkorale, K. (2014) Sources of Ostracism: The Nature and Consequences of Excluding and Ignoring Others. Current Directions in Psychological Science, 23, 93-97. https://doi.org/10.1177/0963721413520321

[2] Twenge, J.M., Catanese, K.R. and Baumeister, R.F. (2003) Social Exclusion and the Deconstructed State: Time Perception, Meaninglessness, Lethargy, Lack of Emotion, and Self-Awareness. Journal of Personality and Social Psychology, 85, 409-423. https://doi.org/10.1037/0022-3514.85.3.409

[3] Sommer, K.L. and Baumeister, R.F. (2002) Self-Evaluation, Persistence, and Performance Following Implicit Rejection: The Role of Trait Self-Esteem. Personality and Social Psychology Bulletin, 28, 926-938. https://doi.org/10.1177/01467202028007006

[4] Baumeister, R.F., Dewall, C.N., Ciarocco, N.J. and Twenge, J.M. (2005) Social Exclusion Impairs Self-Regulation. Journal of Personality and Social Psychology, 88, 
589-604. https://doi.org/10.1037/0022-3514.88.4.589

[5] Baumeister, R.F., Twenge, J.M. and Nuss, C.K. (2002) Effects of Social Exclusion on Cognitive Processes: Anticipated Aloneness Reduces Intelligent Thought. Journal of Personality and Social Psychology, 83, 817-827. https://doi.org/10.1037/0022-3514.83.4.817

[6] Baumeister, R.F. and Tice, D.M. (1990) Point-Counterpoints: Anxiety and Social Exclusion. Journal of Social and Clinical Psychology, 9, 165-195. https://doi.org/10.1521/jscp.1990.9.2.165

[7] Eberharter, V.V. (2011) The Intergenerational Transmission of Economic Disadvantages and Social Exclusion-Constraints on Social Mobility. Journal of Applied Social Science Studies, 131, 287-299.

[8] Mead, N.L., Baumeister, R.F., Stillman,T.F., Rawn, C.D. and Vohs, K.D. (2011) Social Exclusion Causes People to Spend and Consume Strategically in the Service of Affiliation. Journal of Consumer Research, 37, 902-919. https://doi.org/10.1086/656667

[9] Jiang, M., Gao, D.G., Huang, R., DeWall, C.N. and Zhou, X. (2014) The Devil Wears Prada: Advertisements of Luxury Brands Evoke Feelings of Social Exclusion. Asian Journal of Social Psychology, 17, 245-254. https://doi.org/10.1111/ajsp.12069

[10] Ward, M.K. and Dahl, D.W. (2014) Should the Devil Sell Prada? Retail Rejection Increases Aspiring Consumers' Desire for the Brand. Journal of Consumer Research, 41, 590-609. https://doi.org/10.1086/676980

[11] Lee, J. and Shrum, L.J. (2012) Conspicuous Consumption versus Charitable Behavior in Response to Social Exclusion: A Differential Needs Explanation. Journal of Consumer Research, 39, 530-544. https://doi.org/10.1086/664039

[12] Wan, W.E., Xu, J. and Ding, Y. (2014) To Be or Not to Be Unique? The Effects of Social Exclusion on Consumer Choice. Journal of Consumer Research, 40, 1109-1122. https://doi.org/10.1086/674197

[13] Wang, J., Zhu, R. and Shiv, B. (2012) The Lonely Consumer: Loner or Conformer? Journal of Consumer Research, 38, 1116-1128. https://doi.org/10.1086/661552

[14] Williams, K.D. (2007) Ostracism. Annual Review of Psychology, 58, 425-452. https://doi.org/10.1146/annurev.psych.58.110405.085641

[15] Kurzban, R. and Leary, M.R. (2001) Evolutionary Origins of Stigmatization: The Functions of Social Exclusion. Psychological Bulletin, 127, 187-208. https://doi.org/10.1037/0033-2909.127.2.187

[16] MacDonald, G. and Leary, M.R. (2005) Why Does Social Exclusion Hurt? The Relationship between Social and Physical Pain. Psychological Bulletin, 131, 202-223. https://doi.org/10.1037/0033-2909.131.2.202

[17] Williams, K.D. and Jarvis, B. (2006) Cyberball: A Program for Use in Research on Interpersonal Ostracism and Acceptance. Behavior Research Methods, 38, 174-180.

[18] Twenge, J.M., Baumeister, R.F., Tice, D.M. and Stucke, T.S. (2001) If You Can't Join Them, Beat Them: Effects of Social Exclusion on Aggressive Behavior. Journal of Personality and Social Psychology, 81, 1058-1069. https://doi.org/10.1037/0022-3514.81.6.1058

[19] Jiang, H.-Y., Wang, Y. and Ji, F. (2016) The Effect of Social Exclusion on the Activation Strategy of Time-Oriented Mediating Effect of Time-Oriented. Management Review, 11, 95-105.

[20] Williams, K.D. and Sommer, K.L. (1997) Social Ostracism by Coworkers: Does Rejection Lead to Loafing or Compensation? Personality and Social Psychology Bulle- 
tin, 23, 693-706. https://doi.org/10.1177/0146167297237003

[21] Buckley, K.E., Winkel, R.E. and Leary, M.R. (2004) Reactions to Acceptance and Rejection: Effects of Level and Sequence of Relational Evaluation. Journal of Experimental Social Psychology, 40, 14-28. https://doi.org/10.1016/S0022-1031(03)00064-7

[22] Jayati, S. and Wang, J. (2013) How Time Horizon Perceptions and Relationship Deficits Affect Impulsive Consumption. Journal of Marketing Research, 50, 590-605. https://doi.org/10.1177/002224371305000503

[23] Molden, D.C., Lucas, G.M., Gardner, W.L., et al. (2009) Motivations for Prevention or Promotion Following Social Exclusion: Being Rejected versus Being Ignored. Journal of Personality and Social Psychology, 96, 415-431. https://doi.org/10.1037/a0012958

[24] Williams, K.D., Cheung, C.K.T. and Choi, W. (2000) Cyberostracism: Effects of Being Ignored over the Internet. Journal of Personality and Social Psychology, 79, 748-762. https://doi.org/10.1037/0022-3514.79.5.748

[25] Zadro, L., Williams, K.D. and Richardson, R. (2004) How Low Can You Go? Ostracism by a Computer is Sufficient to Lower Self-Reported Levels of Belonging, Control, Self-Esteem, and Meaningful Existence. Journal of Experimental Social Psychology, 40, 560-567. https://doi.org/10.1016/j.jesp.2003.11.006

[26] Baumeister, R.F. and Leary, M.R. (1995) The Need to Belong: Desire for Interpersonal Attachments as a Fundamental Human Motivation. Psychological Bulletin, 117, 497-529. https://doi.org/10.1037/0033-2909.117.3.497

[27] Pickett, C.L., Gardner, W.L. and Knowles, M. (2004) Getting a Cue: The Need to Belong and Enhanced Sensitivity to Social Cues. Personality and Social Psychology Bulletin, 30, 1095-1107. https://doi.org/10.1177/0146167203262085

[28] Brown, S., Kozinets, R.V. and Sherry Jr., J.F. (2003) Teaching Old Brands New Tricks: Retro Branding and the Revival of Brand Meaning. Journal of Marketing, 67, 19-33. https://doi.org/10.1509/jmkg.67.3.19.18657

[29] Jamieson, J.P., Harkins, S.G. and Williams, K.D. (2010) Need Threat Can Motivate Performance after Ostracism. Personality and Social Psychology Bulletin, 36, 690-702. https://doi.org/10.1177/0146167209358882

[30] Holoien, D.S. and Fiske, S.T. (2013) Downplaying Positive Impressions: Compensation between Warmth and Competence in Impression Management. Journal of $E_{X-}$ perimental Social Psychology, 49, 33-41. https://doi.org/10.1016/j.jesp.2012.09.001

[31] Warburton, W.A., Williams, K.D. and Cairns, D.R. (2006) When Ostracism Leads to Aggression: The Moderating Effects of Control Deprivation. Journal of Experimental Social Psychology, 42, 213-220. https://doi.org/10.1016/j.jesp.2005.03.005

[32] Duclos, R., Wan, W.E. and Jiang, Y. (2013) Show Me the Honey! Effects of Social Exclusion on Financial Risk-Taking. Journal of Consumer Research, 40, 122-135. https://doi.org/10.1086/668900

[33] Gerber, J. and Wheeler, L. (2009) On Being Rejected: A Meta-Analysis of Experimental Research on Rejection. Perspectives on Psychological Science, 4, 468-488. https://doi.org/10.1111/j.1745-6924.2009.01158.x

[34] Baumeister, R.F., DeWall, C.N. and Vohs, K.D. (2009) Social Rejection, Control, Numbness, and Emotion: How Not to Be Fooled by Gerber and Wheeler. Perspectives on Psychological Science, 4, 489-493. https://doi.org/10.1111/j.1745-6924.2009.01159.x

[35] Gerber, J.P. and Wheeler, L. (2017) Rejoinder to Baumeister, DeWall, and Vohs 
(2009). Perspectives on Psychological Science, 4, 494-495.

https://doi.org/10.1111/j.1745-6924.2009.01160.x

[36] DeWall, C.N., Baumeister, R.F., Stillman, T.F., and Gailliot, M.T. (2007) Violence Restrained: Effects of Self-Regulation and Its Depletion on Aggression. Journal of Experimental Social Psychology, 43, 62-76. https://doi.org/10.1016/j.jesp.2005.12.005

[37] Wang, Z.W. and Tu, P. (2014) Gender Differences in Self-Concern Changes in Social Exclusion Situations. Journal of Psychology, 46, 1782-1792.

[38] Su, L., Jiang, Y., Chen, Z., et al. (2017) Social Exclusion and Consumer Switching Behavior: A Control Restoration Mechanism. Journal of Consumer Research, 44, 99-117.

[39] Gardner, W.L., Pickett, C.L., Jefferis, V. and Knowles, M. (2005) On the Outside Looking in: Loneliness and Social Monitoring. Personality and Social Psychology Bulletin, 31, 1549-1560. https://doi.org/10.1177/0146167205277208

[40] Maner, J.K., DeWall, C.N., Baumeister, R.F., et al (2007) Does Social Exclusion Motivate Interpersonal Reconnection? Resolving the "Porcupine Problem". Journal of Personality and Social Psychology, 92, 42-55. https://doi.org/10.1037/0022-3514.92.1.42

[41] Brown, S., Kozinets, R.V. and Sherry Jr., J.F. (2003) Teaching Old Brands New Tricks: Retro Branding and the Revival of Brand Meaning. Journal of Marketing, 67, 19-33. https://doi.org/10.1509/jmkg.67.3.19.18657

[42] Duclos, R., Bettman, J.R., Bloom, P.N. and Zauberman, G. (2012) Charitable Giving: How Ego-Threats Impact Donations of Time and Money. Hong Kong University of Science and Technology, Hong Kong.

[43] Liu, Z.L. and Yu, M.Y. (2015) The Impact of Social Exclusion on the Purchase of Anthropomorphic Products: Mediating Effect of Social Characteristics. Modern management Science, 7, 97-99.

[44] White, K. and Argo, J.J. (2009) Social Identity Threat and Consumer Preferences. Journal of Consumer Psychology, 19, 313-325. https://doi.org/10.1016/j.jcps.2009.03.007

[45] Tim, W., Sedikides, C., Arndt, J. and Routledge, C. (2006) Nostalgia: Content: Trigger, Functions. Journal of Personality and Social Psychology, 91, 975-93. https://doi.org/10.1037/0022-3514.91.5.975

[46] Schindler, R.M. and Holbrook, M.B. (2003) Nostalgia for Early Experience as a Determinant of Consumer Preferences. Psychology and Marketing, 20, 275-302. https://doi.org/10.1002/mar.10074

[47] Loveland, K.E., Smeesters, D. and Mandel, N. (2010) Still Preoccupied with 1995 The Need to Belong and Preference for Nostalgic Products. Journal of Consumer Research, 37, 393-408. https://doi.org/10.1086/653043

[48] Epley, N., Adam, W., Akalis, S. and Cacioppo, J.T. (2008) When We Need a Human: Motivational Determinants of Anthropomorphism. Social Cognition, 26, 143-155. https://doi.org/10.1521/soco.2008.26.2.143

[49] Mourey, J.A., Olson, J.G. and Yoon, C. (2017) Products as Pals: Engaging with Anthropomorphic Products Mitigates the Effects of Social Exclusion. Journal Of Consumer Research, 44, 414-431.

[50] Ma, Y., Wang, Q. and Dong, L. (2014) Cheap Superiority: How Social Exclusion Affects the Consumption of New Luxury Goods. Journal of Applied Psychology, 20, 316-322. 
[51] Wang, Y. (2015) The Impact of Social Exclusion on the Willingness of Counterfeit Consumers to Purchase. Shanghai Jiao Tong University, Shanghai.

[52] Wang, Z.W. and Tu, P. (2015) Money or Attention? Sex Differences in Reactions to Social Exclusion. Social Behavior and Personality, 43, 845-854.

https://doi.org/10.2224/sbp.2015.43.5.845

[53] Cacioppo, J.T., Hawkley, L.C., Berntson, G.G., et al. (2002) Do Lonely Days Invade the Nights? Potential Social Modulation of Sleep Efficiency. Psychological Science, 13, 384-387. https://doi.org/10.1111/j.0956-7976.2002.00469.x

[54] Stroud, L.R., Tanofsky-Kraff, M., Wilfley, D.E., et al. (2000) The Yale Interpersonal Stressor (YIPS): Affective, Physiological, and Behavioral Responses to a Novel Interpersonal Rejection Paradigm. Annals of Behavioral Medicine, 22, 204-213. https://doi.org/10.1007/BF02895115 